\title{
Mapeamento dos incêndios residências na área urbana de Santa Maria, RS, Brasil utilizando o estimador de densidade Kernel
}

André Ademir Weber ${ }^{1}$ andre.weber@hotmail.com; Cássio Arthur Wollmann²

\section{RESUMO}

O objetivo deste trabalho é localizar e mapear os incêndios residenciais urbanos em Santa Maria RS, Brasil, entre 2010 e 2013. Para a realização deste estudo foram coletados dados de incêndios dos anos de 2010, 2011, 2012 e 2013 no Quarto Comando Regional dos Bombeiros, e após a coleta e localização dos dados foram estimados densidades de incêndios na área de estudo utilizando o estimador de densidade kernel. Os resultados apontam o que os incêndios são mais frequentes nas regiões Norte e Oeste da cidade, uma vez que nestas áreas o padrão é de edifícios de qualidade inferior e a infraestrutura urbana se apresenta em condições precárias.

Palavras chave: Incêndios residenciais urbanos, Planejamento urbano, Geografia Física.

\section{Mapping of residential fires in the urban area of Santa Maria, RS, Brazil using Kernel density estimator}

\begin{abstract}
The objective of this work is to localize and map the urban residential fires in Santa Maria - RS, Brazil, between 2010 and 2013. For the realization of this study involved collecting fire incident data from the years 2010, 2011, 2012 and 2013 in the Fourth Regional Firefighters Command. After the collection and location of data, densities of fires in the study area using the kernel density estimator were estimated. The results support the argument that fires are more frequent in the city in northwestern area, as in this area the standard of the buildings is of low quality and the urban infrastructure presented is in disrepair.
\end{abstract}

Keywords: residential fires urban, planning urban, Physical Geography.

Recibido el 30 de mayo de 2016; aceptado el 23 de junio de 2016.

\footnotetext{
Programa de Pós-graduação em Geografia, Universidade Federal de Santa Maria. Avenida Roraima, 1000, Cidade Universitária, Bairro Camobi, Santa Maria - RS, 97105-900.

2 Departamento de Geociências,Universidade Federal de Santa Maria.
} 


\section{INTRODUÇÃO}

Em sua gênese a Geografia tem a função de estudar as relações entre a sociedade e a natureza, relações que por muitas vezes podem ser onerosas ao convívio harmônico entre ambos. Nesse sentido, cabe então à Ciência Geográfica a interligação e a resolução dos problemas causados ora pela sociedade, ora pelas manifestações dos fenômenos naturais.

Com o crescente processo de urbanização ocorrido a partir da revolução industrial europeia e a sua intensificação na segunda metade do século passado nos países chamados subdesenvolvidos, as antigas relações entre a sociedade e a natureza foram gradualmente deturpadas, e a cidade passa a ser o palco mais evidente das atividades humanas, sendo elas de cunho social, econômico ou político, refletindo as contradições entre o modelo de desenvolvimento econômico industrial e a realidade de uma crise socioambiental.

A desordenada urbanização engendrou consideráveis alterações da atmosfera urbana, o que levou pesquisadores a observar que o ambiente das cidades tornouse menos sadio em uma proporção inversa a intensificação da urbanização, trazendo consigo a acentuação de problemas e a multiplicação dos casos de desastres, que acompanham a história dos sítios urbanos. Conforme SANTOS (1981), as condições ambientais das cidades quando são ultrajadas, criam uma natureza hostil.

A evolução das cidades, especialmente ao longo do ultimo século, tornaram os incêndios inerentes ao cotidiano das cidades, que historicamente estiveram atrelados ao desenvolvimento e crescimento do fenômeno urbano, onde é possível destacar desde o histórico incêndio de Roma no século I d.C. até o recente desastre na cidade de Valparaíso, no Chile, em 2014.

Nos últimos anos, notou-se um aumento significativo no número de incêndios residenciais no meio urbano de Santa Maria pelos mais diversos motivos, inclusive sendo noticiados pelos meios de comunicação locais (Fig. 1). Porém, quando associados à sucessão dos diferentes tipos de tempos atmosféricos ou às condições climáticas abre-se um novo leque de fatores que podem desencadear esse tipo de desastre, já se observa que nos verões de Santa Maria os incêndios estão associados a intensos períodos de altas temperaturas atrelados às massas tropicais quentes e secas (WEBER et al. 2013).

Os estudos acerca do comportamento espacial dos incêndios no Brasil, assim como no mundo estão concentrados principalmente na temática dos incêndios florestais, ambientais, em unidades de conservação ou em áreas rurais de cultivos arbóreos. De um modo geral as pesquisas orbitam em torno de uma perspectiva ambiental.

Quando levada em consideração a área urbana, os estudos estão detidos em incêndios ambientais dentro das áreas urbanas, ademais os estudos acerca dos incêndios ocorridos em residências levando em conta fatores socioambientais e/ou da concentração espacial deste tipo de fenômeno dentro das áreas urbanas ainda são escassos diante da importância da prevenção deste tipo de desastre.

Os incêndios acabam por constituir eventos catastróficos principalmente no meio urbano, por se tratar de um evento devastador por muitas vezes, ocorrer um curto espaço de tempo. Manifestações desta intensidade são capazes de causar riscos na vida cotidiana citadina, perturbando-a ou desorganizando a circulação e os serviços. Desta maneira CHERUBINI (2014) aponta que os incêndios urbanos podem causar danos humanos, como mortes ou pessoas afetadas, incluindo feridos, enfermos, mutilados, desabrigados, desalojados, desaparecidos; danos materiais, como 


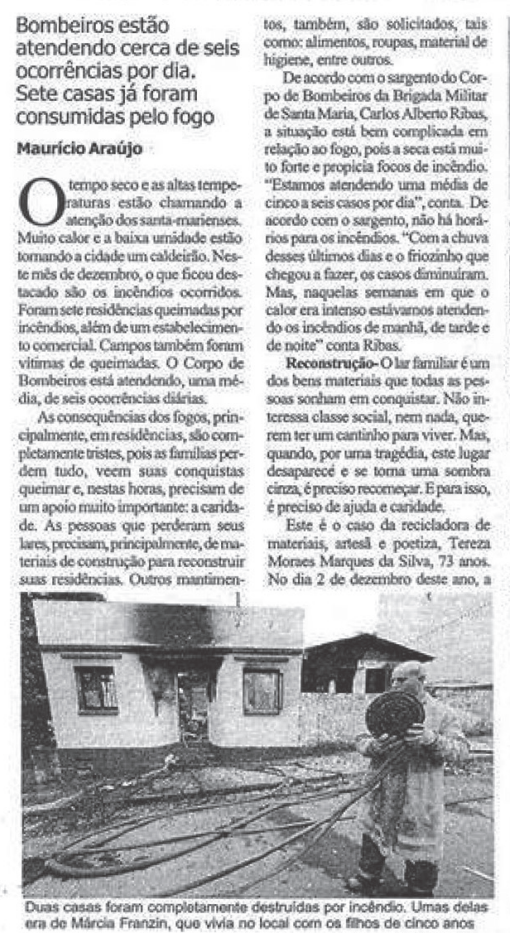

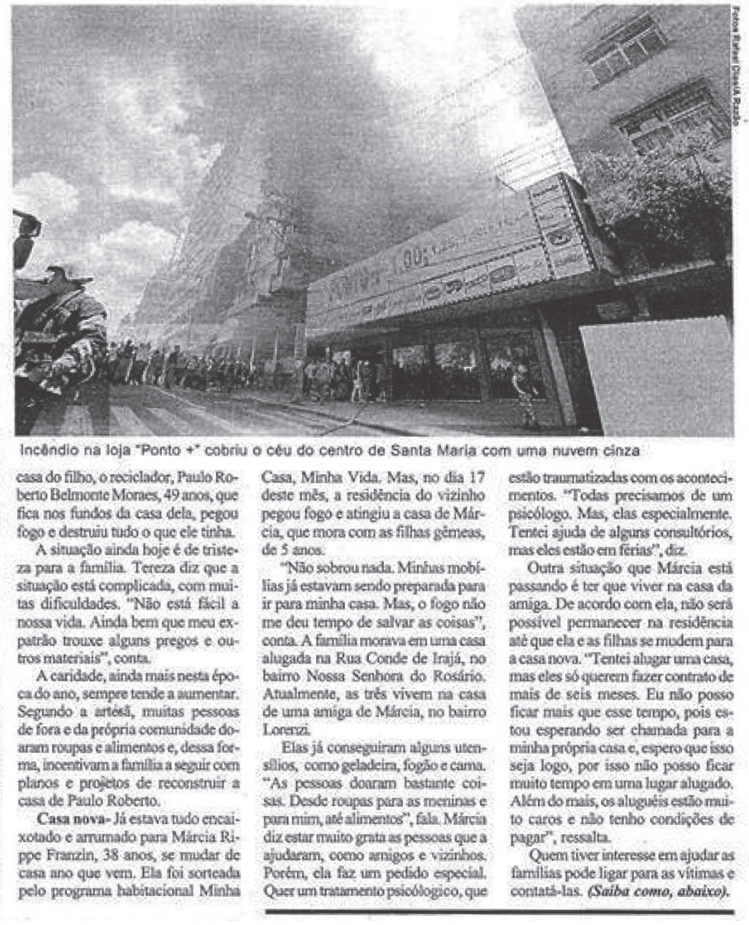

Fig. 1: Número de incêndios no verão chama a atenção da cidade. Fonte: Jornal A razão28/12/2011.

Fig. 1: Summer fires in the city. Source: Jornal A razão- December 28, 2011.

destruição ou danificação de unidades habitacionais, obras de infraestrutura e de instalações públicas e privadas; danos ambientais, como poluição atmosférica; prejuízos econômicos públicos e/ou privados, conforme o tipo de instalação que vierem a afetar.

Segundo ROCHA (2006), define-se risco como a combinação da frequência com a consequeência de eventos indesejáveis, envolvendo algum tipo de perda. Assim, os incêndios podem ser associados as diversas subdivisões dos riscos socioambientais.

Portanto, repensar as cidades para efeito de planejamento sobre uma ótica socioambiental torna-se necessário para o conhecimento sistemático das diferentes funções desenvolvidas no espaço urbano, bem como sua relação com os fatores naturais e sociais ali presentes. Estudar e compreender os elementos e fatores que propiciam e agravam a ocorrência de incêndios é fundamental, pois isso permite, ao longo dos anos, a elaboração e aperfeiçoamento de índices de cálculo de probabilidade e localização de incêndios, MONTOYA \& MARTINEZ (2016) salientam que definitivamente modelos espaciais ajudam a prever áreas potenciais de incêndio de forma mais precisa.

De acordo com COUTO \& CANDIDO (1980), a identificação de locais que apresentam maior risco a incêndios 
facilita o planejamento e as estratégias de prevenção e combate. Para BATISTA (2000), o zoneamento de risco ou os mapas de risco tem sido empregado com muita eficiência como instrumentos fundamentais no planejamento dos recursos destinados a prevenção e pré-sucessão dos incêndios em vegetação. Desta maneira, utilizar esse instrumento na ótica do planejamento urbano pode ser de grande valia, também, para a prevenção e determinação de áreas de risco deste tipo de desastre nas áreas urbanas.

Levando em consideração os aspectos até aqui ponderados, objetivou-se com este trabalho localizar e mapear os incêndios residenciais urbano em Santa Maria RS, Brasil, entre os anos de 2010 e 2013, procurando compreender a distribuição espacial desse tipo de sinistro dentro da área urbana do município, assim como a densidade das ocorrências durante esse período.

\section{MATERIAIS E MÉTODOS}

\section{Caracterização da área de estudo}

O presente trabalho tem como indicador espacial o município de Santa Maria RS, mais precisamente a sua área urbana, localizada no centro geográfico do estado do Rio Grande do Sul, a $29^{\circ} 41^{\prime} 25^{\prime}$ ' de latitude sul e $53^{\circ} 48^{\prime} 42^{\prime}$ " de longitude oeste, conforme demonstra a figura 2 .

De acordo com SARTORI (1979), no quadro morfológico estadual, a região de Santa Maria situa-se na Depressão Periférica Sul Riograndense, também conhecida como Depressão Central, a qual corresponde a uma faixa deprimida, entre relevos mais elevados representados pela escarpa da Serra Geral ao Norte do município. De modo mais específico, o município está localizado, praticamente, na zona de transição entre a Depressão

\section{Localização de Santa Maria, RS - Brasil}

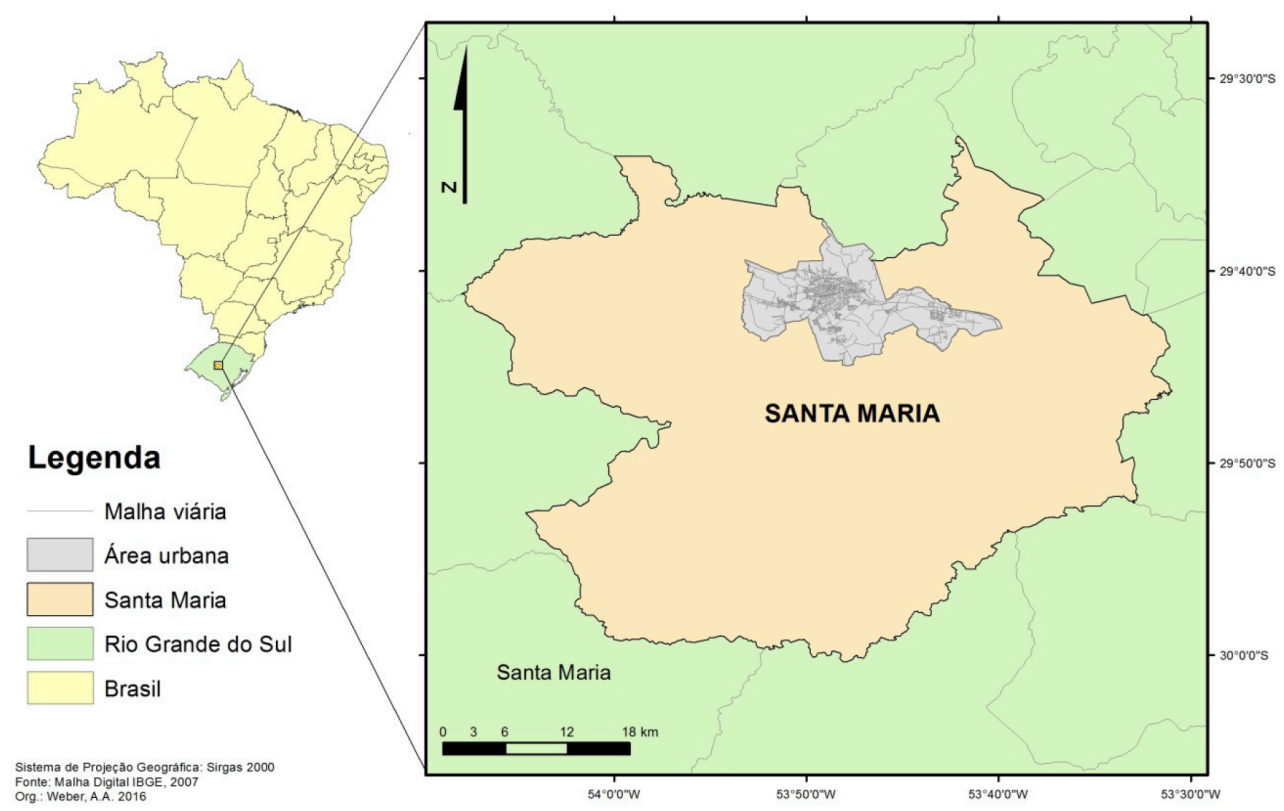

Fig. 2: Localização de Santa Maria.

Fig. 2: Santa Maria location. 
e a escarpa arenito-basáltica do Planalto Meridional Brasileiro.

A área urbana de Santa Maria ocupa uma área sedimentar de topografia suave, encravada entre os contrafortes do Planalto Meridional a Norte e a Noroeste e os morros testemunhos deste situados a leste e a sudeste, tendo uma altitude em média de 110 metros (SARTORI 1979).

Santa Maria é um dos locais mais quentes do Rio Grande do Sul, em função da continentalidade e da baixa altitude, embora a temperatura média anual seja considerada relativamente baixa, se comparada com a média nacional. (COSTA 2009).

Durante o desenrolar do século XX, o crescimento populacional de Santa Maria foi se acentuando, assim como foram se expandindo as edificações da cidade.
Apesar do declínio do setor ferroviário na segunda metade deste mesmo século, a instalação da Base Aérea, do Exército Brasileiro e da Aeronáutica Brasileira, bem como da Universidade Federal de Santa Maria, contribuíram com a ascensão do contingente populacional.

Hoje, Santa Maria é considerada um pólo de ensino, abrigando diversas outras instituições de ensino técnico e superior, e configurando uma extensa rede de serviços e comércio na cidade, que se destacam regionalmente. A população total, segundo o IBGE (2010), é de 261.403 habitantes, dos quais cerca de 50 mil pessoas configuram uma população flutuante e aproximadamente $95 \%$ desta população residem na área urbana se concentrando principalmente no na Região central, norte e oeste da cidade (Fig. 3).

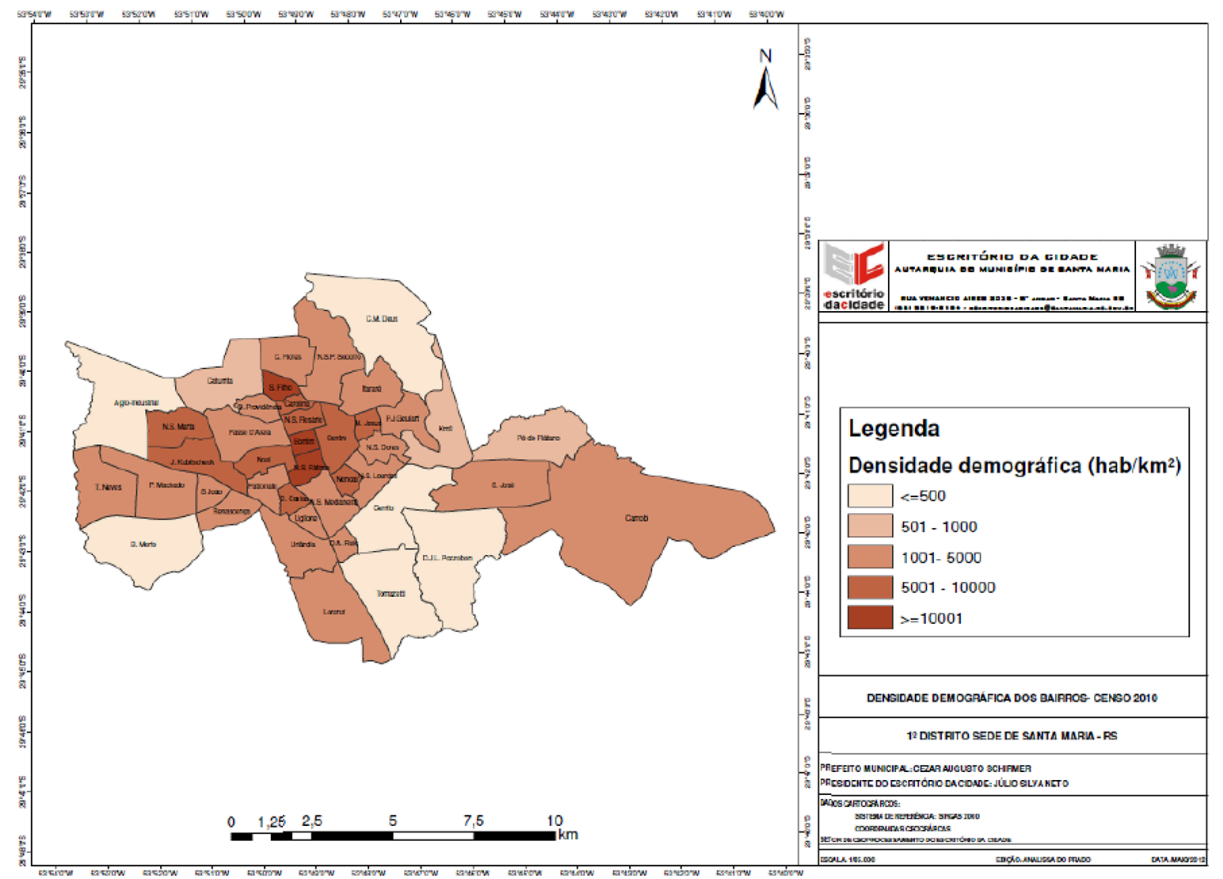

Fig. 3: Mapa de densidade demográfica. Fonte: COMIN (2013).

Fig. 3: Population density map. Souce: COMIN (2013). 
A área urbana de Santa Maria é constituída por quarenta e um bairros distribuídos em oito regiões administrativas: Centro
Urbano, Centro-leste, Centro-Oeste, Leste, Nordeste, Norte, Oeste e Sul (Fig. 4).

\section{Regiões Administrativas da Área Urbana de Santa Maria-RS}

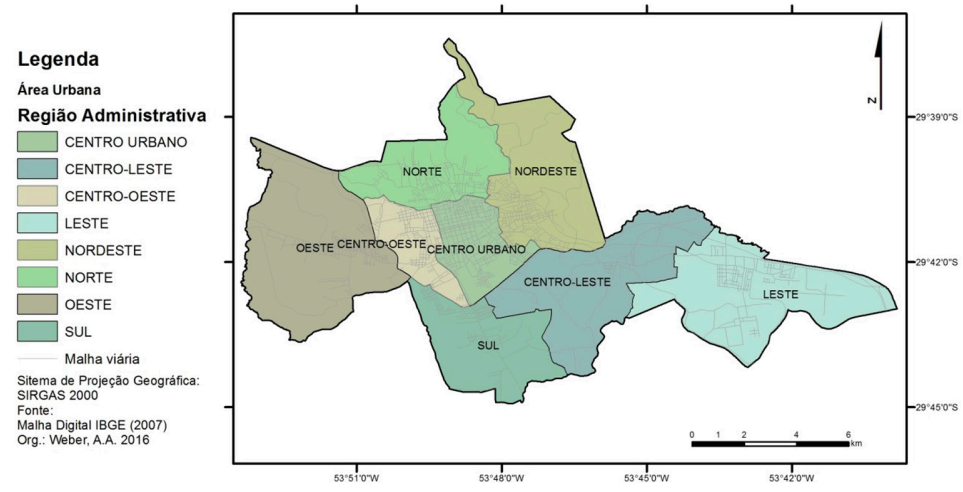

Fig. 4: Localização das regiões administrativas urbanas de Santa Maria-RS.

Fig. 4: Location of urban administrative regions of Santa Maria-RS.

De acordo com PRADO (2012), as regiões administrativas Norte, Oeste e Sul se destacam por possuírem baixas condições de infraestrutura, a presença de diversas áreas ocupadas de forma irregular e de casas construídas no sistema de autoconstrução, ou seja, sem planejamento. Em detrimento, as regiões Centro e Leste são marcadas por apresentarem boas condições de infraestrutura de padrão construtivo das residências. A cidade ainda é marcada por uma alta segregação e concentração de população a partir do seu nível de renda, conforme demonstra a figura 5 .

O autor ainda destaca que Santa Maria possui uma estrutura residencial urbana determinada pela classe alta, pois tal classe seleciona como local de residência as áreas mais atrativas, geralmente dotadas de ampla infraestrutura e em locais ambientalmente privilegiados (longe de riscos de desastres socioambientais) como as regiões centro, centro-leste e leste; fazendo com que as demais classes sociais se distribuam no restante do espaço urbano de forma desigual e fragmentada.

\section{Sobre o estimador de densidade Kernel}

Quando estudamos processos pontuais como no caso dos incêndios residenciais, podemos estimar o número esperado de eventos por unidade de área, ou seja, a intensidade. Há diversos métodos para estimar a intensidade através de interpolações tais como Krigeagem, superfície de tendência, modelos locais de regressão e estimador kernel (SANTOS et al. 2012).

Estas técnicas aplicadas ao conjunto de eventos pontuais resultam em um mapa de contorno de intensidade estimada em ocorrências em toda área, o Mapa de Kernel é uma alternativa para análise geográfica do comportamento de padrões. Para o presente trabalho foi utilizado o estimador de densidade kernel para determinação de padrões de pontos dentro da área de estudo presente na extensão SpatialAnalyst do software ArcGis 10 versão Studentedition.

Em inglês, a palavra Kernel significa núcleo. No contexto das Geotecnologias esse termo faz referência a um método estatístico 


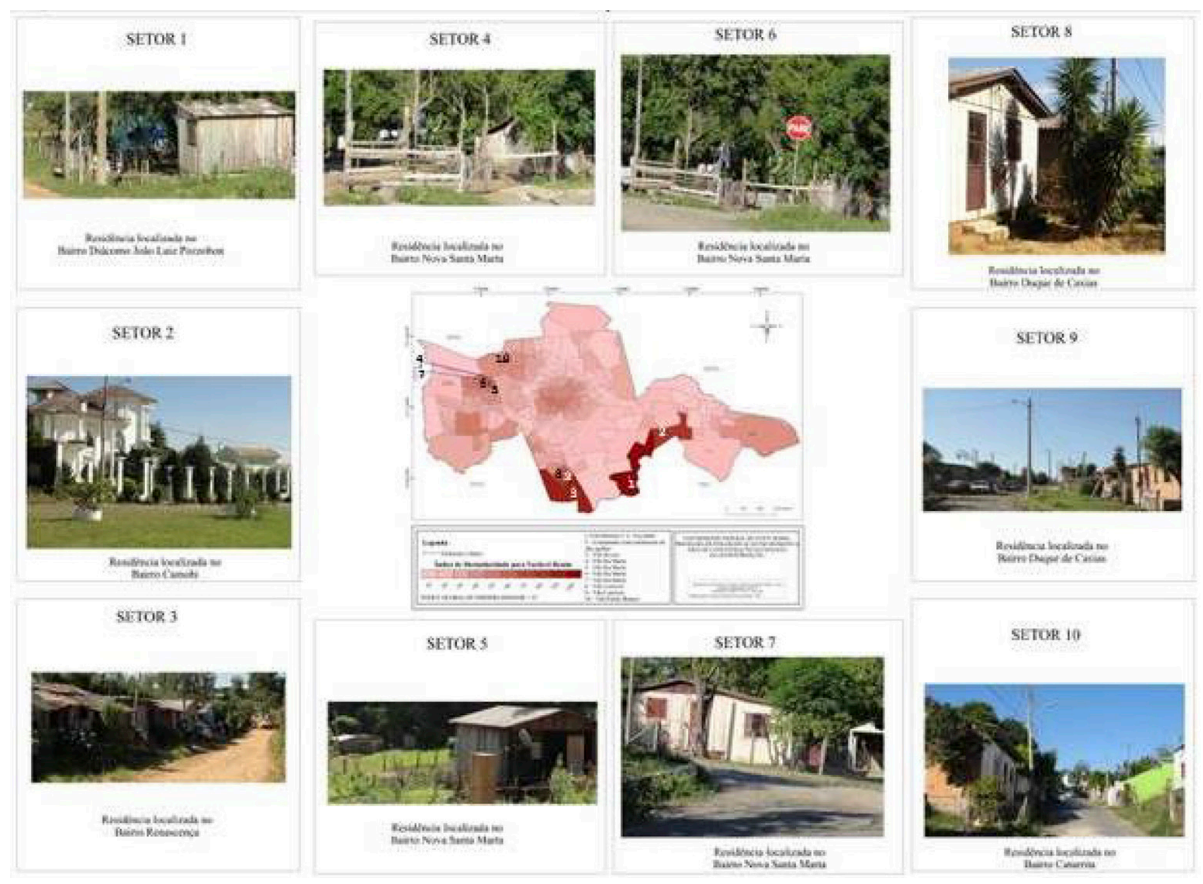

Fig. 5: Identificação dos setores censitários com maior dissimilaridade de renda local e fotos do tipo de residência e infraestrutura do entorno. Fonte: PRADO (2012).

Fig. 5: Identification of census sectors with the greastest differences in local income and photos of the type of residence and infraestructure environment. Source: PRADO (2012).

de estimação de curvas de densidades. O método kernel é muito utilizado para mapear e estimar a forma de distribuição dos pontos no espaço e é amplamente utilizado para a localização e adensamento de incêndios florestais e/ou em áreas rurais, porém não é muito utilizado para a determinação de adensamentos de incêndios residenciais em áreas urbanas.

O estimador de densidade Kernel se trata de um método não paramétrico para estimação de curvas de densidades, em que cada observação é ponderada pela distância em relação a um valor central, o núcleo. A ideia é centrar cada observação $\mathrm{x}$ onde se queira estimar a densidade, uma janela $b$ que define a vizinhança de $\mathrm{x}$ e os pontos que pertencem à estimação, ou seja, é uma técnica de análise espacial que se baseia na criação de superfícies de densidade (SOUTO MAIOR \& CÂNDIDO 2014).
O estimador desenha uma vizinhança circular ao redor de cada ponto da amostra, correspondendo ao raio de influência, e então é aplicada uma função matemática de 1 , na posição do ponto a 0 , na fronteira da vizinhança. O valor para a célula é a soma dos valores Kernel sobrepostos e divididos pela área de cada raio de pesquisa (SILVERMAN 1986) como demonstrado pela figura 6 :

Essa estimativa é apropriada para posições de dados individuais; entretanto, podese adotar esta técnica se o interesse é mostrar regiões menos fragmentadas de um determinado evento ou conjunto de eventos (ALVES et al. 2010), como no caso dos incêndios o objetivo é localizá-los e agrupálos em regiões de maior concentração, pois quando existe uma concentração excessiva de pontos a visualização fica comprometida. Assim, o estimador se torna uma excelente 


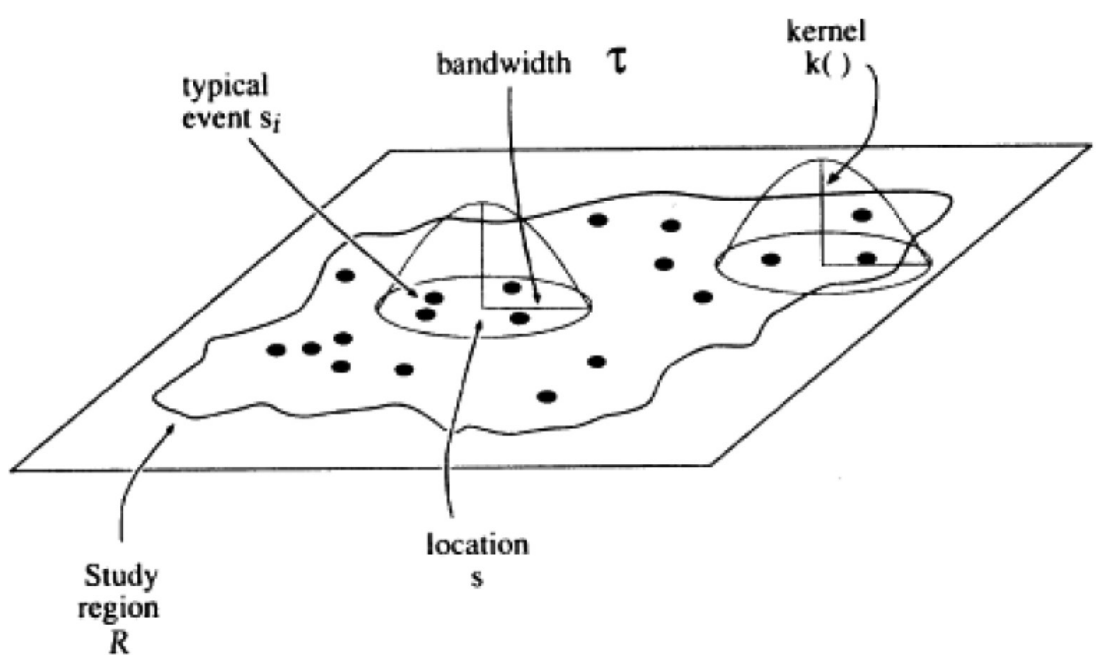

Fig. 6: Estimador de intensidade para um padrão de pontos. Fonte: TERUIYRA (1999).

Fig. 6: Intensities estimator for a pattern of dots. Source: TERUIYRA (1999).

ferramenta para evidenciar as regiões com maior ocorrência deste tipo de desastre, pois também a representação não fica limitada a áreas pré-definidas, como é o caso de polígonos de bairros ou municípios.

OMapa de Kernel, passa a seruma alternativa para análise geográfica do comportamento de padrões. O mapa é plotado, por métodos de interpolação, a intensidade pontual de determinado fenômeno em toda a região de estudo. Assim, temos uma visão geral da intensidade do processo em todas as regiões do mapa.

A partir deste método, foi criado um mapa classificado com níveis de densidades que variam de acordo com a cor e tonalidade sendo representados: Vermelho significa densidade muito alta; Laranja indica densidade alta; Amarela densidade média; Verde com tonalidade mais clara significa densidade baixa e Verde com tonalidade mais escura densidade muito baixa.

Isso auxilia na analise, pois visualmente quando detectado uma faixa com uma tonalidade ou cor mais intensa (vermelha, por exemplo), existe uma concentração elevada, pois os pontos segregados estão muito próximos criando este tipo de resultado, permitindo que se possa inferir que nesta região (SOUZA et al. 2013).

\section{RESULTADOS}

Para a realização do presente trabalho foram, primeiramente, coletados junto ao $4^{\circ}$ Comando Regional de Bombeiros o número de incêndios residenciais dos anos 2010, 2011, 2012 e 2013. Ressalta-se que só foram computados os dados relativos a incêndios urbanos ocorridos em residências, sendo casas ou prédios, descartando os dados de incêndios ambientais em áreas desabitadas. Após o levantamento e localização dos dados foram estimadas as suas densidades, ou a quantidade de ocorrência do evento em determinada região da cidade.

Faz-se necessário ressaltar o trabalho do $4^{\circ}$ Comando regional de Bombeiros de Santa Maria em realizar o levantamento dos dados referentes aos incêndios residenciais urbanos entre 2010 e 2013. Durante esse período de tempo foram contabilizados um total de 161 incêndios residenciais na área urbana de Santa Maria nos mais diversos bairros e regiões administrativas, conforme demonstra a figura 7 . 


\section{Localização dos incêndios residênciais entre 2010 e 2013}

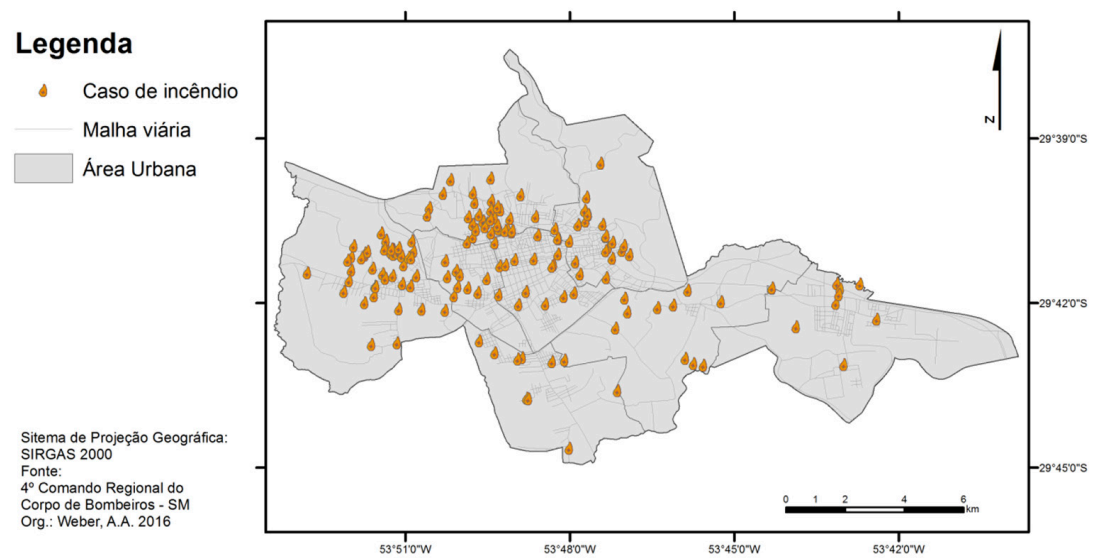

Fig. 7: Localização dos incêndios residenciais entre 2010 e 2013 em Santa Maria - RS.

Fig. 7: Location of residential fires between 2010 and 2013 in Santa Maria - RS.

Pode-se observar claramente uma maior concentração dos eventos nas regiões Oeste e Norte da cidade, indicados pelos bairros Nova Santa Marta, Salgado Filho, Caturrita e Carolina, diferentemente da região leste representado pelo bairro Camobi, assim como no Centro, onde o número de eventos contabilizados é bem menor que os demais bairros.
A elaboração do mapa de densidade (Fig. 8) ilustra a densidade das ocorrências de incêndios residenciais em Santa Maria. O mapa demonstra as áreas da cidade com maior ocorrência de incêndios, indicada pelas áreas em vermelho, e quanto mais próximas ao verde menor é incidência desse tipo de risco de origem antrópica.

\section{Densidade de incêndios residenciais entre 2010 e 2013}

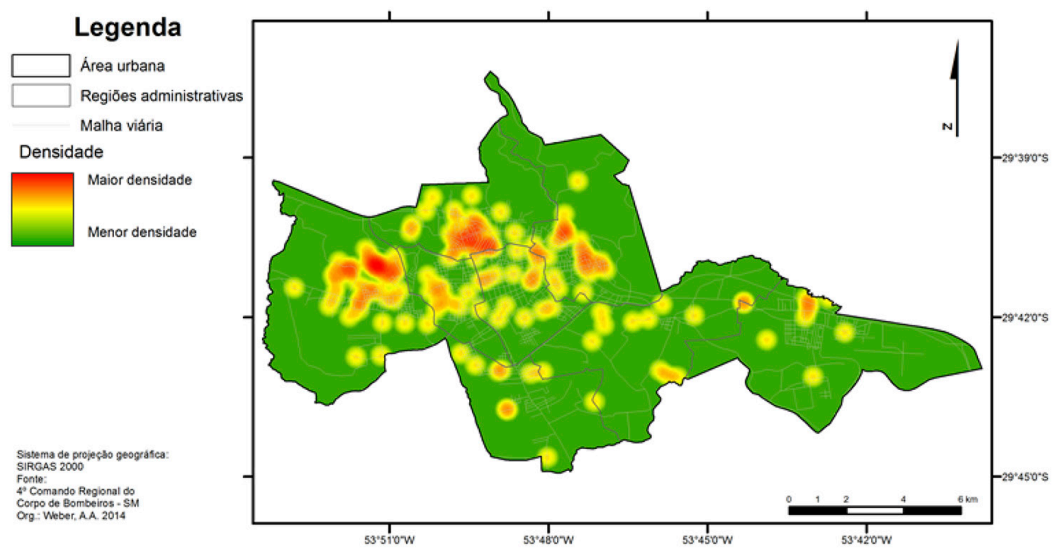

Fig. 8: Densidade das ocorrências de Incêndios residenciais entre 2010 e 2013.

Fig. 8: Residential ocurrences density fires between 2010 and 2013. 


\section{DISCUSSÃO}

A utilização do estimador de densidade kernel possibilitou a visualização do adensamento do número de incêndios dentro da área urbana de Santa Maria, permitindo estipulação de um padrão no comportamento espacial dos incêndios residenciais. Com a utilização do estimador foi possível evidenciar que os incêndios têm maior ocorrência em um eixo Norte-Oeste da cidade em primeiro plano e nas regiões Centro Urbano, Centro Oeste e Nordeste em segundo plano.

A incidência de incêndios guarda relação com as vulnerabilidades do cenário urbano, por atingirem, com frequência, assentamentos precários (CHERUBINI 2014). Dentre os desequilíbrios mais visíveis, que podem vir a desencadear um desastre dessa natureza, podem ser mencionados, no caso de assentamentos precários, alta densidade populacional conjugada com vulnerabilidade econômica e social, implicando deficientes condições estruturais das habitações, com uso de materiais de construção que facilitam a combustão. Assim observando o mapa de densidade demográfica (Fig. 3), é possível perceber a ocorrência de incêndios nas áreas onde existe uma maior concentração populacional.

Destaca-se, também, que nas áreas, Oeste e Norte, o padrão construtivo é de menor qualidade assim como a infraestrutura urbana se apresenta em condições inferiores como demonstrado anteriormente. Salientase também o maior número de instalações elétricas irregulares assim como a instalação elétrica residencial de menor qualidade que podem desencadear um número maior de incêndios. Ao contrário, as Regiões Leste, Centro-leste e Sul que apresentam um padrão construtivo mais alto e melhores condições de estrutura urbana não apresentaram uma concentração significativa de incêndios.

\section{CONCLUSÕES}

Ao mapear as ocorrências de incêndio evidenciou-se que a maior ocorrência está nas Regiões Oeste e Norte da cidade, principalmente nos Bairros Nova Santa Marta, Carolina, Salgado Filho e Caturrita, isso pode ocorrer por esses bairros apresentarem um padrão construtivo das residências é mais baixo. Percebeu-se ainda uma densidade maior de incêndios onde ocorre uma maior concentração populacional dentro da área urbana, evidenciado pelas ocorrências nas regiões Centrais e Nordeste.

Embora a metodologia apresentada não seja amplamente utilizada para verificar a densidade de incêndios em uma área urbana, quando utilizada dentro das cidades essa metodologia se torna capaz de definir o comportamento dos incêndios e a localização da maior parte deles, quando cruzado com dados como padrão construtivo ou adensamento populacional essa técnica pode facilitar a definição de áreas com maior risco de incêndios assim como na definição de estratégias de combate e prevenção desse tipo de desastre.

Torna-se importante salientar que o estimador de densidade kernel é uma ferramenta que auxilia o estudo do comportamento espacial dos incêndios, porém ele não deve ser utilizado como única forma de análise, pois é necessário conhecer também aspectos socioeconômicos, demográficos e da constituição área urbana para estabelecer padrões de incidência dos incêndios.

O conhecimento desses fatores torna-se de grande importância no contexto atual, onde se busca uma melhora na qualidade e preservação da vida da população em geral, observando que grande parte dos desastres deu-se em bairros onde as condições econômicas são baixas e as estruturas precárias. Espera-se, assim, que este trabalho possa servir de suporte para futuros trabalhos dentro da Ciência Geográfica e do planejamento urbano. 


\section{REFERÊNCIAS}

ALVES, H. P. F., A. Y. MELLO, A.O. D'ANTONA \& R.L. DO CARMO, 2010. Vulnerabilidade socioambiental nos municípios do litoral paulista no contexto das mudanças climáticas. In: Anais XVII Encontro Nacional de Estudos Populacionais, Caxambu.

BATISTA, A. C., 2000. Mapas de risco: uma alternativa para o planejamento de incêndios florestais. Floresta, 30: 45-54.

COSTA, E. R., 2009. O campo termohigrotérmico intra-urbano e a formação de ilhas de calor e frescor urbanas em Santa Maria - RS. Universidade Federal de Santa Maria, Santa Maria - Inédita.

COMIN, F V., 2013. Dinâmica espacial e segregação residencial no bairro Camobi Santa Maria/RS. Universidade Federal de Porto Alegre, Porto Alegre - Inédita.

COUTO, E. A. \& J. F. CÂNDIDO, 1980. Incêndios florestais. Imprensa Universitária UFV, Viçosa.

CHERUBINI, K.G., 2014. Incêndios Urbanos. Revista Jus Navegandi. jus.com. br/artigos/31197/incendios-urbanos.

\section{INSTITUTO BRASILEIRO DE} GEOGRAFIA E ESTATÍSTICA (IBGE). 2010. Cidades. http://cidades.ibge.gov. $\mathrm{br} /$ painel/painel.php?lang $=\& \operatorname{codmun}=4$ $31690 \&$ search $=$ rio-grande-do-sul|santamaria|infograficos:-dados-gerais-domunicipio.

MENDONÇA, F. A., 1994. Geografia e meio ambiente. Contexto. São Paulo.

MONTOYA, J.L.I. \& F.M.H. MARTINEZ, 2016. Modelado espacial de incendios: una herramienta predictiva para el Bosque La Primavera, Jalisco México. Ambiente \& Água - An Interdisciplinary Journal of Applied Science, 11:35-49.

PRADO, T.C.S., 2012. Segregação residencial por índice de dissimilaridade, isolamento e exposição, com indicador renda no espaço urbano de Santa Maria - RS, por geotecnologias. Universidade Federal de Santa Maria, Santa Maria - Inédita.

ROCHA, G.C., 2006. Riscos ambientais: análise e mapeamento em Minas Gerais. Editora UFJF, Juiz de Fora.

SARTORI, M. G. B., 1979. O clima de Santa Maria, RS: do regional ao urbano. Universidade de São Paulo, São Paulo Inédita.

SANTOS, M., 1981. Manual de Geografia Urbana. HUCITEC, São Paulo.

SANTOS, B. S., R. L. SANTOS \& S. M. SANTO, 2012. Análise Espacial Aplicada à Expansão de Condomínios Fechados na Cidade de Feira de Santana (BA). In: IV Simpósio Brasileiro de Ciências Geodésicas e Tecnologias da Geoinformação, Recife.

SOUZA, N. P., E. M. G. C. SILVA \& M.D. TEIXEIRA, 2013. Aplicação do Estimador de Densidade kernel em Unidades de Conservação na Bacia do Rio São Francisco para análise de focos de desmatamento e focos de calor. In: Anais XVI Simpósio Brasileiro de Sensoriamento Remoto SBSR, Instituto Nacional de Pesquisas Espaciais, Foz do Iguaçu: 4958-4965.

SILVERMAN, B. W., 1986. Density Estimation for Statistics and Data Analysis. Chapman and Hall, New York.

SOUTO MAIOR, M.M. \& G. A. CÂNDIDO, 2014. Avaliação das metodologias brasileiras de vulnerabilidade 
socioambiental como decorrência da problemática urbana no Brasil. Cadernos Metrópole, 16: 241-264.

TERUIYA, R.K., 1999. Análise explioratória de dados sócio-econômicos do município do Rio de Janeiro. Instituto Nacional de Pesquisas Espaciais, São José dos Campos.

WEBER, A.A., C. A. WOLLMANN \& A.C. IENSE, 2013. O estudo do ritmo climático e sua influência nos incêndios residenciais urbanos em Santa Maria - RS. Ciência e Natura, 36: 393-407.
WOLLMANN, C. A., 2009. Frequência mensal e sazonal da participação de sistemas atmosféricos no verão do Rio Grande do Sul: análise sobre três casos típicos (1986/1987, 1997/1998 e 2004/2005). Ciência e Natura, 31:141-161. 